\title{
METABOLIC SYNDROME AND RISK FACTORS FOR NON-ALCOHOLIC FATTY LIVER DISEASE
}

\author{
Mônica Rodrigues de Araújo SOUZA, Margareth de Fátima Formiga de Melo DINIZ, \\ José Eymard Moraes de MEDEIROS-FILHO and Maria Salete Trigueiro de ARAÚJO
}

\begin{abstract}
Context - Non-alcoholic fatty liver disease (NAFLD), hepatic manifestation of metabolic syndrome, has been considered the most common liver disease nowadays, which is also the most frequent cause of elevated transaminases and cryptogenic cirrhosis. The greatest input of fatty acids into the liver and consequent increased beta-oxidation contribute to the formation of free radicals, release of inflammatory cytokines and varying degrees of hepatocytic aggression, whose histological expression may vary from steatosis (HS) to non-alcoholic steatohepatitis (NASH). The differentiation of these forms is required by the potential risk of progression to cirrhosis and development of hepatocellular carcinoma. Objective - To review the literature about the major risk factors for NAFLD in the context of metabolic syndrome, focusing on underlying mechanisms and prevention. Method - PubMed, MEDLINE and SciELO data basis analysis was performed to identify studies describing the link between risk factors for metabolic syndrome and NAFLD. A combination of descriptors was used, non-alcoholic fatty liver disease, non-alcoholic steatohepatitis, metabolic syndrome and risk factors. At the end, 96 clinical and experimental studies, cohorts, meta-analysis and systematic reviews of great impact and scientific relevance to the topic, were selected. Results - The final analysis of all these data, pointed out the central obesity, type 2 diabetes, dyslipidemia and hypertension as the best risk factors related to NAFLD. However, other factors were highlighted, such as gender differences, ethnicity, genetic factors and the role of innate immunity system. How these additional factors may be involved in the installation, progression and disease prognosis is discussed. Conclusion - Risk factors for NAFLD in the context of metabolic syndrome expands the prospects to 1) recognize patients with metabolic syndrome at high risk for NAFLD, 2) elucidate pathways common to other co-morbidities, 3) determine risk factors associated with a worse prognosis, 4) develop therapeutic strategies with goal of reducing risk factors, 5) apply acquired knowledge in public health policies focusing on preventive strategies.
\end{abstract}

HEADINGS - Metabolic syndrome X. Fatty liver, non-alcoholic. Risk factors.

\section{INTRODUCTION}

Clinical importance of non-alcoholic fatty liver disease NAFLD has grown in recent years, mainly in consequence of the obesity epidemics, sedentary habits and high calorie diet adopted by people of Western countries, reflecting the increase in cardiovascular and endocrine-metabolic diseases ${ }^{(30)}$. It has been considered the most common liver disease and the most frequent cause of elevated aminotransferase and cryptogenic cirrhosis $^{(19,20,21)}$. The prevalence of NAFLD has been estimated in $2.8 \%$ to $88 \%$, depending on population and investigative methods ${ }^{(2,7,9,19,21,48)}$. NAFLD refers to fat accumulation, mainly triglycerides, in hepatocytes so that it exceeds $5 \%$ of the liver weight ${ }^{(2)}$. Available data from clinical, experimental and epidemiological studies describe the NAFLD as the hepatic manifestation of metabolic syndrome (MS) ${ }^{(59)}$. Main risk factors associated with metabolic syndrome are abdominal obesity, insulin resistance, diabetes and dyslipidemia ${ }^{(73)}$.
Interestingly, NAFLD can be described in non-obese and non-diabetic patients ${ }^{(50)}$.

The first Brazilian guidelines for diagnosis and treatment, based on systematic reviews, defines metabolic syndrome as a complex disorder represented by a set of cardiovascular risk factors, usually related to central fat deposition and insulin resistance. Its importance should be highlighted from an epidemiological standpoint, responsible for increased general and cardiovascular mortality estimated at 1.5 times and 2.5 times, respectively ${ }^{(29)}$. Patients with NAFLD exhibit a higher mortality rate than general population ${ }^{(1)}$. The most frequent causes of death are represented by liver-related diseases, malignant neoplasms and cardiovascular disease ${ }^{(83)}$. Although not part of the diagnostic criteria for metabolic syndrome, several clinical and pathophysiological conditions are often associated with it, such as polycystic ovary syndrome, acanthosis nigricans, fatty liver disease, microalbuminuria, prothrombotic states, pro-inflammatory states and endothelial dysfunction and hyperuricemia ${ }^{(8,62)}$. 
NAFLD's pathogenic mechanisms are still under investigation; however, triglycerides accumulation within hepatocytes, result of insulin resistance, is considered the first step in the pathogenic model proposed and widely accepted so far. Oxidative stress resulting from mitochondrial oxidation of fatty acids and expression of inflammatory cytokines, have been considered secondary causal factors for liver damage, fibrosis and inflammation ${ }^{(25)}$.

Histological evaluation remains the most important method of distinguishing steatosis from advanced forms of NAFLD, i.e. non-alcoholic steatohepatitis (NASH) and fibrosis. Included NAFLD lesions are steatosis, lobular and portal inflammation, hepatocyte injury as ballooning and apoptosis, and fibrosis ${ }^{(10)}$. In the latter are included inflammatory phenomena with elevated aminotransferase levels ${ }^{(4)}$, often associated with increased fat intake or changes in metabolic processes, with involvement of the mitochondrial beta-oxidation of fatty acids, generating reactive oxygen species and increasing the production of inflammatory cytokines. These, in turn, represent important role in activation of stellate cells, inducing liver fibrogenesis, predisposing to cirrhosis and hepatocellular carcinoma ${ }^{(21)}$; however, risk factors for this progression have not been fully established ${ }^{(43)}$.

\section{METHODS}

A PubMed, MEDLINE and SciELO data basis analysis was performed to identify studies describing the link between risk factors for MS and NAFLD. Search terms included "Non-alcoholic fatty liver disease, non-alcoholic steatohepatitis, metabolic syndrome AND risk factors". Additional searches were also made for each of the individual methods described, e.g. NAFLD and obesity, diabetes, hypertension, genetic factors, etc. Selected articles referenced in these publications were also examined. Using the search strategy described above, approximately 130 articles were considered, limited to those published in English, Spanish and Portuguese language but not date-restricted. Following review, 96 articles met the selection criteria and were included, clinical and experimental studies, cohorts, meta-analysis and systematic reviews of great impact and scientific relevance to the topic.

\section{Obesity}

Obesity is a major public health problem in the U.S. and its prevalence has increased significantly over the past 30 years. Obesity is a global epidemic with more than 1 billion overweight adults and at least 300 million obese patients worldwide ${ }^{(17)}$. Information collected from 1999 to 2002 shows that more than one third of American adult population is obese (27.6\% men and $33.2 \%$ women) and among children, one in six is overweight ${ }^{(6)}$. In previous reports, other authors have reported NAFLD prevalence around $57 \%$ to $74 \%$ and $22 \%$ to $58 \%$ of obese children and adults, respectively ${ }^{(71,81)}$.

A cross-sectional population-based study was carried out in a sample of 1720 adults between 20 to 59 years of age, residents in an urban area of Brazil. The prevalence of central obesity was 50.5\% (95\% CI: 46.6-54.4) among men and 38.9\% (95\% CI 34.4-43.5) among women. In the adjusted analysis, central higher prevalence of obesity was observed in women aged 50 to 59 years ${ }^{(27)}$.

Steatohepatitis, however, can be found in $40 \%$ to $100 \%$ obesity cases in adults ${ }^{(81)}$ and $15 \%$ to $25 \%$ in children ${ }^{(70)}$. Considering obesity as a growing epidemic condition, the prevalence and impact of NAFLD continues to increase, making NASH potentially the most common cause of advanced liver disease in coming decades ${ }^{(85)}$.

A clinical series in Korean patients revealed that the body mass index (BMI) was useful in distinguishing between NASH and simple steatosis. In this study, 28.9 BMI was suggested as a threshold for NASH. It was proposed that abdominal fat is directly associated with disease state ${ }^{(73)}$. Waist circumference and waist/hip ratio were independent determinants of hepatic necro-inflammation degree ${ }^{(77)}$. A $158 \mathrm{~cm}^{2}$ of visceral fat area was considered an independent predictor of risk disease ${ }^{(78)}$. Dorsocervical lipo-hypertrophy has also been strongly linked to $\mathrm{NASH}^{(15)}$. A positive correlation was found between adiposity indexes (BMI, serum cholesterol and LDL levels) and advance stage fibrosis ${ }^{(73)}$.

\section{Obesity and ethnicity}

Demographic analysis of obese populations added impressive evidence of how ethnic variations can influence extent and NASH incidence. Steatohepatitis is common among Hispanic populations, probably due to the high obesity level in this ethnic group ${ }^{(9)}$. Despite the high prevalence of other risk factors, such as type 2 diabetes, NASH prevalence in African-American population is not so high, this could explain the significantly lower chance to developing serious liver disease, compared to caucasian patients ${ }^{(40)}$. In two series of patients with NASH and another one with cryptogenic cirrhosis, African-Americans accounted for only $1 \%$ and $0.6 \%$ of those groups, respectively ${ }^{(11)}$. Solga et al. ${ }^{(79)}$ presented a study in which steatohepatitis was completely absent in obese African-Americans. It is speculated that both genetic and environmental factors (eg. eating habits) may be related to decreased incidence of liver disease in this ethnic population. Little information is available about the NASH prevalence in Western countries. A multicenter epidemiological Brazilian study involving 1280 patients with NAFLD described obesity prevalence in $44.7 \%$ of the studied sample ${ }^{(23)}$. In another Brazilian study, the prevalence of hepatic steatosis among obese adolescents was estimated at $70 \%$ and $40 \%$ for males and females, respectively ${ }^{(24)}$. In an American school-bases sample obese adolescent boys have an increased prevalence of fatty liver compared with obese adolescent girls ${ }^{(75)}$.

\section{Hypoxia, obesity and sleep apnea}

The obstructive sleep apnea (OSA) is a commonly condition associated with obesity. It is characterized by chronic intermittent breathing cessation during sleep due to airway obstruction, occurring in $2 \%$ to $4 \%$ overall population. Tanné et al. ${ }^{\left({ }^{(0)}\right.}$ reported higher prevalence and severity of NASH in patients with severe OSA, suggesting that intermittent 
hypoxia may play a role in the NASH pathogenesis. Although intermittent hypoxia does not cause direct liver damage in non-obese animals, necro-inflammation and fibrosis were observed in livers of animals that already had steatosis, suggesting that hypoxia may serve as an additional insult in the progression from simple steatosis to more advanced stages of the disease ${ }^{(74,94)}$.

Data derived from a PubMed-based meta-analysis of recent cost effectiveness, standards of practice, and epidemiological studies of OSA, which were ranked using a hierarchical strength of recommendation taxonomy, presents evidence supporting the value of diagnosing and treating OSA in reducing morbidity and mortality, improving comorbid disease processes, and improving patient quality of life $\mathrm{e}^{(68)}$.

\section{Birth weight}

The association between an adverse early life environment and increased susceptibility to later-life metabolic disorders such as obesity, type 2 diabetes and cardiovascular disease was described by the developmental origins of health and disease hypothesis. A systematic review summarizes the relationship of both low birth weight and catch-up-growth with some aspects of a later metabolic syndrome. The majority of the studies in children, adolescents and adults born small for gestational age suggested that insulin resistance could represent the prelude to other metabolic disorders ${ }^{(6)}$. Meta-analysis of 224 studies estimated the association between birth weight and MS. All but two studies reported an inverse relationship between birth weight and MS. A comparison between low birth weight versus normal birth weight subjects showed the random effects odds ratio for metabolic syndrome was 2.53 ( $95 \%$ CI: $1.57 ; 4.08)$, indicating that low birth weight increases the risk of metabolic syndrome in adults ${ }^{(76)}$.

Employing a rat model of maternal high fat (MHF) nutrition, it was recently reported that offspring born to exposed mothers are small at birth and develop a postnatal phenotype that closely resembles that of the human metabolic syndrome. Livers of offspring born to MHF mothers also display a fatty phenotype reflecting hepatic steatosis and characteristics of non-alcoholic fatty liver disease. In this study it was hypothesised that a MHF diet leads to altered regulation of liver development in offspring; a derangement that may be detectable during early postnatal life ${ }^{(32)}$.

\section{Gender and age}

There are clear differences in the amount and distribution of body fat between men and women. The first usually store fat in the upper body, specifically around the organs in the abdominal cavity: the visceral fat. However women, with less body fat, tend to store in the subcutaneous tissue. Gender also influences the lipids circulation (triglycerides and fatty acids), lipoproteins and cholesterol ${ }^{(73,84,90)}$.

The reasons for the difference in fat accumulation in men and women are not completely understood; however, evidence suggests that lipid metabolism may play an important role in the differences observed ${ }^{(73)}$. At the cellular level, there are distinctions between men and women in activity and metabolism of lipids. A Japanese study showed that the particle size of triglyceride and cholesterol were higher in men than women, with evidence of metabolic syndrome ${ }^{(51)}$. Comparing by age group, the hepatic lipase activity in men is twice that observed in women, which probably contributes to an atherogenic lipid profile with lower HDL cholesterol and increased levels of dense LDL particles in men ${ }^{(12)}$.

Gender distinctions in hepatic lipase activity have been attributed to the suppression of androgenic steroids and visceral adiposity ${ }^{(73)}$. Studies in rats and mice have shown worsening of biochemical and histopathological patterns in male rodents ${ }^{(49)}$. However, researches towards defining gender role in NASH in humans are scarce and limited and the available information is contradictory.

An American study including 365 adults revealed NASH prevalence in $90 \%$ of men and $30.8 \%$ of women. Males were also significantly associated with incidence of diabetes and metabolic syndrome ${ }^{(3)}$. Studies conducted in pediatric patients also reported that males are at greater risk of obesity and associated liver disease ${ }^{(54)}$. In contrast to the evidence described for the Western population, a series of 193 Japanese patients had NASH proven by histopathology predominantly in women aged above 55 years ${ }^{(91)}$. In Brazil, mean age of patients with NAFLD was $49.8 \pm 13.59$ years, of which $53.3 \%$ were male ${ }^{(23,76)}$.

On the other hand, several reports with different ethnic groups can not identify the difference between men and women, excluding the possibility of inferring any conclusions about the role of gender as a risk factor for NASH ${ }^{(73)}$.

Regarding age, it is known that aging brings restrictions on physical mobility, which in the context of metabolic syndrome, contributes to maintenance or worsening of abdominal obesity, hyperglycemia, hyperlipidemia and hypertension ${ }^{(69)}$. The prevalence of metabolic syndrome among Americans over 70 years was estimated at around $42 \%{ }^{(37)}$. In another study NAFLD was associated with increased risk of cardiovascular disease especially among older patients with elevated C-reactive protein levels ${ }^{(16)}$.

\section{Diabetes}

Insulin resistance and hyperinsulinemia are the most closely associated laboratory findings with the presence of fatty liver disease in a large series of patients, even in thin subjects with normal glucose tolerance ${ }^{(8,41,59)}$. NAFLD prevalence is increased in individuals with impaired glucose tolerance and those with newly diagnosed diabetes at the proportion of $43 \%$ to $62 \%$, respectively ${ }^{(48)}$. In a prospective study of 100 patients with type 2 diabetes, the incidence of hepatic steatosis was $49 \%$, confirming this strong independent risk factor for NAFLD ${ }^{(41)}$. In Brazil, the prevalence of metabolic syndrome and diabetes among patients with NAFLD was estimated at $41.3 \%$ and $22.7 \%$, respectively ${ }^{(23)}$. The association of both conditions is related with more aggressive disease and increasing mortality ${ }^{(34,93)}$. Targher et al. ${ }^{(82)}$ described increased prevalence of NAFLD and its association with cardiovascular disease in diabetic patients independent of other confounding factors. 
Frequency and risk factors associated with NAFLD in patients with type 2 diabetes mellitus was studied. Almost half of patients with type 2 diabetes mellitus were found to have NAFLD, and they have more elevated BMI, as well as higher levels of aminotransferases, $\gamma$-GT, uric acid, TNF- $\alpha$, insulin and HOMA-IR than subjects without NAFLD ${ }^{(36)}$.

A possible pathogenic link between diabetes and NASH involves advanced glycation end products. These products constitute a large variety of substances formed from aminocarbonyl interactions of non-enzymatic nature, among reducing sugars or oxidized lipids and proteins, aminophospholipids or nucleic acids ${ }^{(64)}$. The formation of these adducts occurs at high rates in diabetes mellitus type 2, compared with healthy controls or patients with simple steatosis ${ }^{(47)}$. The interaction of these products with the cell surface associated receptor has been related to induction of oxidative stress and as well as the increased fibrogenic potential stellate cells cultures ${ }^{(35)}$. The interaction of these advanced glycation products and cell surface receptors resulted in intermediate reactive oxygen species, which has important role in the disease pathogenesis in diabetic ${ }^{(73)}$.

\section{Hypertension}

Hypertension, especially systolic hypertension is also an independent NAFLD predictor ${ }^{(29)}$. The presence of multiple metabolic disorders like diabetes mellitus, obesity, dyslipidemia and hypertension are associated with serious illness, potentially progressive of liver ${ }^{(61)}$. Cotrim et al. ${ }^{(23)}$ confirmed these data when reporting 64\% hypertension prevalence among NAFLD patients steatohepatitis. Hsiao et al. ${ }^{(46)}$ demonstrated that presence of severe hepatic steatosis was significantly correlated with the prevalence and degree of hypertension, serum glucose levels and triglycerides. On the other hand, a study on non-obese and non-diabetic patients with primary hypertension has shown that hepatic steatosis prevalence can double as compared with control group ${ }^{(31)}$.

A meta-analysis compared individuals with metabolic syndrome and without revealed an increased mortality from all causes (relative risk [RR] 1.35; 95\% confidence interval [CI], 1.17-1.56) and cardiovascular disease (RR 1.74; 95\% CI, 1.29-2.35); as well as an increased incidence of cardiovascular disease (RR 1.53; 95\% CI, 1.26-1.87), coronary heart disease (RR 1.52; 95\% CI, 1.37-1.69) and stroke (RR 1.76; 95\% CI, 1.37-2.25). Relative risk of cardiovascular disease associated with metabolic syndrome was higher in women compared with men and higher in studies that used World Health Organization definition compared with studies that used Adult Treatment Panel III definition ${ }^{(38)}$.

Li et al. ${ }^{(5)}$ investigated by meta-analysis the association between MS and risk of stroke. Compared to individuals without MS, patients had a 1.6-fold increased risk of stroke (95\% CI, 1.48-1.75). The relative risk of stroke associated with MS was 2.2 in the studies using the World Health Organization definition and 1.6 in those using Adult Treatment Panel III definition, but difference was not statistically significant.
Abnormalities in left ventricular geometry and diastolic function have been described in patients with NAFLD as well as a more severe coronary artery disease characterized by vulnerable plaques, though observed in small cohort studies $^{(83)}$.

\section{Dyslipidemia}

Increased serum triglycerides and low-density lipoproteins (LDL), combined with decreased high-density lipoproteins (HDL), represent a threat for cardiovascular disease development. Evidences suggest that NAFLD is linked to the increased incidence of cardiovascular disease, both in non-diabetic and type 2 diabetic patients ${ }^{(52)}$.

The presence of dyslipidemia (hypercholesterolemia, hypertriglyceridemia, or both) defined by the National Institute of Health (NIH) ${ }^{(65)}$ was reported in $20 \%$ to $80 \%$ cases associated with NAFLD ${ }^{(6,28,57)}$. Hypertriglyceridemia is present in $64 \%$ of patients with hepatic steatosis with low HDL-C levels reported in 30\%-42\% of cases ${ }^{(60)}$. Cotrim et al. ${ }^{(23)}$, reported the presence of hyperlipidemia in $66.8 \%$ of patients with NAFLD in Brazil. Recent studies have shown NAFLD strongly associated with increased risk of cardiovascular disease, there being independent association between hepatic steatosis, carotid atherosclerotic plaques and endothelial dysfunction $^{(86,87)}$. Considering all liver related causes, cardiovascular disease represents the major survival risk of patients with $\mathrm{NASH}^{(33)}$. On the other hand, McKimmie et al. ${ }^{(63)}$ did not find independent association between hepatic steatosis and cardiovascular disease in a subset of participants in Diabetes Heart Study. They suggested that hepatic steatosis is more a secondary phenomenon than a direct mediator of cardiovascular disease.

\section{Evidence of endocrine system role in the pathogenesis of non-alcoholic fatty liver disease}

Evidence shows that chronic activation of hypothalamicpituitary-adrenal axis is present in metabolic syndrome, like patients with Cushing's syndrome that also have similar characteristics of metabolic syndrome and mild increase of aminotransferase levels being commonly seen in patients with adrenal insufficiency as well as adult patients with growth hormone deficiency who develop the phenotype of metabolic syndrome with obesity and dyslipidemia ${ }^{(14)}$.

Insulin resistance, type 2 diabetes, sleep apnea syndrome, cardiovascular disorders and non-alcoholic liver disease are common conditions in women with polycystic ovary syndrome, being non-alcoholic fatty liver disease twice as common in postmenopausal women in which hormone replacement therapy reduces the risk of steatosis. Similarly, it seems appropriate to consider polycystic ovary syndrome as the ovarian manifestation of metabolic syndrome ${ }^{(5)}$.

Hypoandrogenism in males and hyperandrogenism in females are also related to hepatic steatosis, obesity and insulin resistance $^{(42)}$. Meta-analysis of available cross-sectional data suggests that MS can be associated to male hypogonadism, although only few randomized controlled trials have been 
reported. Testosterone replacement therapy seems to improve metabolic control, as well as central obesity ${ }^{(22)}$.

Thyroid hormones play essential role in mobilization and degradation of lipids and fatty acid oxidation so that hypothyroidism has been associated with non-alcoholic steatohepatitis ${ }^{(56)}$. There is evidence that replacement of thyroid hormones regulates lipid metabolism ${ }^{(96)}$. However, it is unclear whether thyroid dysfunction plays a role in the NASH pathogenesis. Liangpunsakul and Chalasani ${ }^{(56)}$ conducted a case-control study to investigate this association. In this study, the prevalence of hypothyroidism in NAFLD patients was estimated at $15 \%$, significantly higher than in controls $(7.2 \%, P<0.001)$. By multivariate analysis, hypothyroidism prevalence in NASH group was significantly higher than in control group.

The association between thyroid diseases and hepatocellular carcinoma in men and women was studied ${ }^{(44)}$. Authors found a significant association between increased risk of hypothyroidism and hepatocellular carcinoma in women, regardless establishing hepatocellular carcinoma risk factors. However, experimental investigations are needed for complete evaluation of the association between these two diseases.

Changes of the endocrine system should be considered in the context of non-alcoholic and cryptogenic fatty liver disease. The prospect of endocrine system participation may help in therapeutic approaches in the future ${ }^{(57)}$.

\section{Genetic factors}

Not all patients with risk factors for metabolic syndrome develop hepatic steatosis and among them, not all evolve to steatohepatitis or cirrhosis. Genetic polymorphisms can explain these variations ${ }^{(26)}$.

Weltman et al. ${ }^{(88,89)}$ working on experimental and human models of steatohepatitis, had previously described the overexpression of cytochrome P450 CYP2E1, with generation of excess oxygen free radicals. Increased CYP2E1 expression induced by alcohol, ketone and free fatty acids was associated with overproduction of oxygen free radicals and increased oxidative stress.

In NAFLD, genetic factors are not fully known; however, it was suggested that steatosis development may be associated with genes involved in insulin resistance coding for proteins involved in lipid metabolism, oxidative stress, inflammation (cytokines and adipokines) and fibrogenesis ${ }^{(18}$ ${ }^{45)}$. Other genetic polymorphisms have been reviewed, such as angiotensinogen and TGF- $\beta 1$ associated with liver fibrosis in obese patients ${ }^{(32)}$.

Chalasani et al. ${ }^{(13)}$ in a pilot study, identified genetic variations associated with histological parameters in patients with NAFLD biopsy-proven. NAFLD histological activity score was associated with single nucleotide polymorphism (SNP) rs2645424 on chromosome 8, degree of fibrosis was associated with SNP rs343062 on chromosome 7 and lobular inflammation was associated with single nucleotide polymorphism in chromosomes 10, 11 and 12. If future studies validate these results, then testing should be clinically useful, since histologic findings are associated with NAFLD prognosis. Mutations in HFE gene of hemochromatosis and NASH have been described, mainly by establishing connections between increased iron stores in the liver and development of hepatic fibrosis. George et al. ${ }^{(39)}$ studying 51 patients with NASH, demonstrated that 31 had mutation in HFE gene being considered heterozygous for hemochromatosis. Authors argue that iron overload, even light, can act synergistically in promoting fibrosis observed in NASH. However, posterior studies $^{(18,92)}$ found no association between increased iron and fibrosis, questioning its importance as NASH risk factor. After having systematically reviewed the most studied single nucleotide polymorphisms and metabolic syndrome associations, it was found evidence for an association with the MS for eight alleles, mostly located in genes involved in lipid metabolism ${ }^{(70)}$. Thus, genetic studies are needed to identify new genes involved in the NAFLD development.

\section{Orthotopic liver transplantation (OLT)}

There are few published studies that have specifically reported the development of individual components of metabolic syndrome following OLT. The prevalence of post-transplant metabolic syndrome and its individual components has been found to be higher post-OLT versus a comparable population without this surgical procedure. The rate of metabolic syndrome in liver transplant recipients is more than twice that reported for general population ${ }^{(53)}$. Pre-transplant risk factors include immunosuppression, higher age at transplant, male gender, history of smoking, pre-transplant body mass index, preOLT diabetes, etiology of the underlying liver disease that resulted in OLT and an increased donor body mass index ${ }^{(67)}$. Recent data suggests that prospective studies are required to determine the significance and management of post-transplant metabolic syndrome ${ }^{(53)}$ and NAFLD.

\section{Smoking}

Smoking history was associated with advanced liver fibrosis in a large multicenter cohort of NAFLD patients ${ }^{(95)}$. The results indicate that smoking may enhance progression of NAFLD partly through its effect on insulin resistance. This was the first study to show that cigarette smoking is associated with increased fibrosis severity in human NALFD, suggesting it may accelerate disease progression. These results may support a formal recommendation of smoking cessation in patients with NAFLD.

\section{CONCLUSION}

NAFLD may affect any age and seems to be different among different ethnic groups. Prevalence is significantly higher in white man than in white women. Differences in body fat distribution and body composition among ethnic groups may partially explain racial differences in prevalence. Central obesity phenotype is associated with increased intra-abdominal fat, therefore, patients with central obesity are characteristically insulin resistant, and more commonly present with NAFLD compared to patients having lower-body obesity. Besides central obesity, type 2 diabetes, dyslipidemia 
and hypertension are risk factors for development of NAFLD, represents more than a clinical diagnosis, being a pre-morbid condition with high rate of cardiovascular, renal, and liver risks. Environmental and lifestyle-related factors such as reduced physical activity and high-fat diets are well-known influences for development of insulin resistance-associated comorbidities and NAFLD. Genetic predisposition for the development of central obesity and type 2 must be considered. Recent findings have advanced in the field of genetic and immune response (innate immunity) in NASH pathogenesis, although family studies and studies specifically addressing the genetic susceptibility for NAFLD development are lacking. Prospects remain to: 1) elucidate pathways common to other co-morbidities, 2) establish more accurate and less invasive diagnostic tools, 3) determine risk factors related to outcomes of poor prognosis, 4) develop therapeutic strategies aiming to reduce risk factors, 5) apply the acquired knowledge in public health policies focusing on preventive strategies.

Souza MRA, Diniz MFFM, Medeiros-Filho JEM, Araújo MST. Síndrome metabólica e fatores de risco para a doença hepática gordurosa não-alcoólica. Arq Gastroenterol. 2012;49(1):89-96.

RESUMO - Contexto - A doença hepática gordurosa não alcoólica (DHGNA) vem sendo considerada a manifestação hepática da síndrome metabólica e a hepatopatia mais frequente da atualidade, sendo também a causa mais frequente de aumento das transaminases e de cirrose criptogênica. O maior aporte de ácidos graxos ao fígado e consequente aumento da beta-oxidação concorrem para formação de radicais livres, liberação de citocinas inflamatórias e graus variáveis de agressão hepatocítica, cuja expressão histológica pode variar da esteatose hepática (EH) à esteatohepatite nãoalcoólica (EHNA), cuja diferenciação se faz necessária pelo risco potencial de progressão para cirrose e desenvolvimento do carcinoma hepatocelular. Objetivo - Revisar a literatura sobre os principais fatores de risco para a DHGNA no contexto da síndrome metabólica, com foco nos mecanismos subjacentes e nas estratégias de prevenção. Método - Foi realizada pesquisa bibliográfica no PubMed para identificar estudos que descrevessem a associação entre os fatores de risco para síndrome metabólica e a DHGNA, utilizando-se a combinação de descritores: "Non-alcoholic fatty liver disease, Non-alcoholic steatohepatitis, metabolic syndrome and risk factors". Foram selecionados 96 estudos clínicos, experimentais, de cohort, metanálises e revisões sistemáticas de maior impacto e relevância científica para o tema. Resultados - A análise das informações consolidou a obesidade central, diabetes melitus tipo 2, dislipidemia e hipertensão como os fatores de risco mais bem relacionados à DHGNA. Entretanto, outros fatores foram destacados, como diferenças entre gêneros, etnia, fatores genéticos e o papel da imunidade inata, como estes fatores adicionais que podem estar implicados na instalação, progressão e prognóstico da doença. Conclusão - O conhecimento dos fatores de risco para a DHGNA no contexto da síndrome metabólica amplia os caminhos para: 1) reconhecer pacientes com risco elevado para a doença; 2) elucidar vias comuns a outras comorbidades; 3) determinar fatores de risco relacionados a pior prognóstico; 4) desenvolver estratégias terapêuticas com o objetivo de reduzir fatores de risco; 4) aplicar os conhecimentos adquiridos nas políticas públicas de saúde com foco em estratégias preventivas.

DESCRITORES - Síndrome X metabólica. Fígado gorduroso não-alcoólico. Fatores de risco.

\section{REFERENCES}

1. Adams LA, Lymp JF, St Sauver J, Sanderson SO, Lindor KD, Feldstein A, Angulo P. The natural history of nonalcoholic fatty liver disease: a population-based cohort study. Gastroenterology. 2005;129:113-21.

2. Angulo P. GI epidemiology: nonalcoholic fatty liver disease. Aliment Pharmaco Ther. 2007;25:883-9.

3. Arun J, Clements RH, Lazenby AJ, Leeth RR, Abrams GA. The prevalence of nonalcoholic steatohepatitis is greater in morbidly obese men compared to women. Obes Surg. 2006;16:1351-8.

4. Bacon BR, Farahvash MJ, Janney CG, Neuschwander-Tetri BA. Nonalcoholic steatohepatitis: an expanded clinical entity. Gastroenterology. 1994;107:1103-9.

5. Baranova A, Tran TP, Birerdinc A, Younossi ZM. Systematic review: association of polycystic ovary syndrome with metabolic syndrome and non-alcoholic fatty liver disease. Aliment Pharmacol Ther. 2011;33:801-14.

6. Baskin ML, Ard J, Franklin F, Allison DB. Prevalence of obesity in the United States. Obes Rev. 2005;6:5-7.

7. Bedogni G, Miglioli L, Masutti F, Tiribelli C, Marchesini G, Bellentani S. Prevalence of and risk factors for nonalcoholic fatty liver disease: the Dionysos nutrition and liver study. Hepatology. 2005;42:44-52.

8. Bloomgarden ZT. Definitions of the insulin resistance syndrome: the 1st World Congress on the Insulin Resistance Syndrome. Diabetes Care. 2004;27:824-30.

9. Browning JD, Szczepaniak LS, Dobbins R, Nuremberg P, Horton JD, Cohen JC, Grundy SM, Hobbs HH. Prevalence of hepatic steatosis in an urban population in the United States: impact of ethnicity. Hepatology. 2004;40:1387-95.

10. Brunt EM, Tiniakos DG. Histopathology of nonalcoholic fatty liver disease. World J Gastroenterol. 2010;16:5286-96.
11. Caldwell SH, Harris DM, Patrie JT, Hespenheide EE. Is NASH underdiagnosed among African Americans? Am J Gastroenterol. 2002;96:1496-1500.

12. Carr MC, Ayyobi AF, Murdoch SJ, Deeb SS, Brunzell JD. Contribution of hepatic lipase, lipoprotein lipase, and cholesteryl ester transfer protein to LDL and HDL heterogeneity in healthy women. Arterioscler Thromb Vasc Biol. 2002;22:667-73.

13. Chalasani N, Guo X, Loomba R, Goodarzi MO, Haritunians T, Kwon S, Cui J, Taylor KD, Wilson L, Cummings OW, Chen YD, Rotter JI. Genome-wide association study identifies variants associated with histologic features of nonalcoholic fatty liver disease. Gastroenterology. 2010;139:1567-76.

14. Chanson P, Salenave S. Metabolic syndrome in Cushing's syndrome. Neuroendocrinology. 2010;92(Suppl 1):96-101.

15. Cheung O, Kapoor A, Puri P, Sistrun S, Luketic VA, Sargeant CC, Contos MJ, Shiffman ML, Stravitz RT, Sterling RK, Sanyal AJ. The impact of fat distribution on the severity of nonalcoholic fatty liver disease and metabolic syndrome. Hepatology. 2007;46:1091-100.

16. Chiang CH, Huang CC, Chan WL, Chen JW, Leu HB. The severity of nonalcoholic fatty liver disease correlates with high sensitivity $\mathrm{C}$-reactive protein value and is independently associated with increased cardiovascular risk in healthy population. Clin Biochem. 2010;43:1399-404

17. Chiang DJ, Pritchard MT, Nagy LE. Obesity, diabetes mellitus, and liver fibrosis. Am J Physiol Gastrointest Liver Physiol. 2011;300:G697-702.

18. Chitturi S, Weltman M, Farrell GC, McDonald D, Kench J, Liddle C, Samarasinghe D, Lin R, Abeygunasekera S, George J. HFE mutations, hepatic iron, and fibrosis:ethinic-specific association of NASH with C82Y but not with fibrotic severity. Hepatology. 2002;36:142-9.

19. Clark JM, Brancati FL, Diehl AM. The prevalence and etiology of elevated aminotransferase levels in the United States. Am J Gastroenterol. 2003;98:960-7. 
20. Clark JM, Diehl AM. Nonalcoholic fatty liver disease: an underrecognized cause of cryptogenic cirrhosis. JAMA. 2003;289:3000-4

21. Clark JM. The epidemiology of nonalcoholic fatty liver disease in adults. J Clin Gastroenterol. 2006;40(3 Suppl 1):s5-10.

22. Corona G, Monami M, Rastrelli G, Aversa A, Tishova Y, Saad F, Lenzi A, Fort G, Mannucci E, Maggi M. Testosterone and metabolic syndrome: a meta-analysis study. J Sex Med. 2011;8:272-83.

23. Cotrim HP, Parise ER, Oliveira CP, Leite N, Martinelli A, Galizzi J, Silva R de C, Mattos A, Pereira L, Amorim W, Ivantes C, Souza F, Costa M, Maia L, L, Pessoa M, Oliveira F. Nonalcoholic fatty liver disease in Brazil. Clinical and histological profile. Ann Hepatol. 2011;10:33-37.

24. Dâmaso AR, Tock L, Tufik S, Prado WL, Stella SG, Fisberg M, Cintra IP, Caranti DA Siqueira KO, Nascimento CM, Oyama LM, Lederman HM, Cristofalo D, Antunes HK, Comparoni A, Santos LC, Meloo MT. Tratamento multidisciplinar reduz o tecido adiposo visceral, leptina, grelina e a prevalência de esteatose hepática não alcoólica (NAFLD) em adolescentes obesos. Rev Bras Med Esporte. 2006;12:263-67.

25. Day CP, James OF. Steatohepatitis: a tale of two "hits"? Gastroenterology. 1998; $114: 842$.

26. Day CP. The potential role of genes in nonalcoholic fatty liver disease. Clin Liver Dis. 2004;8:673-91.

27. de Sousa TF, Nahas MV, Silva DA, Del Duca GF, Peres MA. Factors associated with central obesity in adults from Florianópolis, Santa Catarina: a population based-study. Rev Bras Epidemiol. 2011;14:296-309.

28. Diehl AM, Goodman Z, Ishak KG. Alcohollike disease in nonalcoholics. A clinica and histological comparison with alcohol-induced liver injury. Gastroenterology. 1988;94:1056-62.

29. Diretriz Brasileira de Diagnóstico e Tratamento da Síndrome Metabólica I [Internet]. Arq Bras Cardiol. 2005;84:3-28.

30. Dixon JB, Bhathal PS, O'Brien PE. Nonalcoholic fatty liver disease: predictors of nonalcoholic steatohepatitis and liver fibrosis in the severely obese. Gastroenterology. 2001;121:91-100.

31. Donati G, Stagni B, Piscaglia F, Venturoli N, Morselli-Labate AM, Rasciti L, Bolondi L. Increased prevalence of fatty liver in arterial hypertensive patients with normal liver enzymes: role of insulin resistance. Gut. 2004;53:1020-3.

32. Dowman JK, Tomlinson JW, Newsome PN. Pathogenesis of non-alcoholic fatty liver disease. QJM. 2010;103:71-83.

33. Dudley KJ, Sloboda DM, Connor KL, Beltrand J, Vickers MH. Offspring of mothers fed a high fat diet display hepatic cell cycle inhibition and associated changes in gene expression and DNA methylation. PLoS One. 2011;6:e21662.

34. Ekstedt M, Franzén LE, Mathiesen UL, Thorelius L, Holmqvist M, Bodemar G Kechagias S. Long-term follow-up of patients with NAFLD and elevated liver enzymes. Hepatology. 2006;44:865-73.

35. Fehrenbach H, Weiskirchen R, Kasper M, Gressner AM. Up-regulated expression of the receptor for advanced glycation end products in cultured rat hepatic stellate cells during transdifferentiation to myofibroblasts. Hepatology. 2001;34:943-952.

36. Ferreira VSG, Pernambuco RB, Lopes EP, Morais CN, Rodrigues MC, Arruda MJ, Silva LM, Vilar L. Frequency and risk factors associated with non-alcoholic fatty liver disease in patients with type 2 diabetes mellitus. Arq Bras Endocrinol Metab. 2010;54;362-8.

37. Ford ES, Giles WH, Dietz WH. Prevalence of the metabolic syndrome among US adults: findings from the third National Health and Nutrition Examination Survey. JAMA. 2002;287:356-9.

38. Galassi A, Reynolds K, He J. Metabolic syndrome and risk of cardiovascular disease: a meta-analysis. Am J Med. 2006;119:812-9.

39. George DK, Goldwurm S, MacDonald GA, Cowley LL, Walker NI, Ward PJ, Jazwinska EC, Powell LW. Increased hepatic iron concentration in nonalcoholic steatohepatitis is associated with increased fibrosis. Gastroenterology. 1998;114:311-8.

40. Giday SA, Ashiny Z, Naab T, Smoot D, Banks A. Frequency of nonalcoholic fatty liver disease and degree of hepatic steatosis in African-American patients. J Natl Med Assoc. 2006;98:1613-5.

41. Gupte P, Amarapurkar D, Agal S, Baijal R, Kulshrestha P, Pramanik S, Patel N, Madan A, Amarapurkar A, Hafeezunnisa. Non-alcoholic steatohepatitis in type 2 diabetes mellitus. J Gastroenterol Hepatol. 2004;19:854-8.

42. Hagymási K, Reismann P, Rácz K, Tulassay Z. [Role of the endocrine system in the pathogenesis of non-alcoholic fatty liver disease]. Orv Hetil. 2009; 150:2173-81.

43. Hashizume H, Sato K, Takagi H, Hirokawa T, Kojima A, Sohara N, Kakizaki S, Mochida Y, Shimura T, Sunose Y, Ohwada S, Mori M. Primary liver cancers with nonalcoholic steatohepatitis. Eur J Gastroenterol Hepatol. 2007;19:827-4.

44. Hassan MM, Kaseb A, Li D, Patt YZ, Vauthey JN, Thomas MB, Curley SA, Spitz MR, Sherman SI, Abdalla EK, Davila M, Lozano RD, Hassan DM, Chan W, Brown TD, Abbruzzese JL. Association between hypothyroidism and hepatocellular carcinoma: a case-control study in the United States. Hepatology. 2009; 49:1563-70
45. Hijona E, Hijona L, Arenas JI, Bujanda L. Inflammatory mediators of hepatic steatosis. Mediators Inflamm. 2010;2010:837419.

46. Hsiao PJ, Kuo KK, Shin SJ, Yang YH, Lin WY, Yang JF, Chiu CC, Chuang WL, Tsai TR, Yu ML. Significant correlations between severe fatty liver and risk factors for metabolic syndrome. J Gastroenterol Hepatol. 2007;22:2118-23.

47. Hyogo H, Yamagishi S, Iwamoto K, Arihiro K, Takeuchi M, Sato T, Ochi H, Nonaka M, Nabeshima Y, Inoue M, Ishitobi T, Chayama K, Tazuma S. Elevated levels of serum advanced glycation end products in patients with non-alcoholic steatohepatitis. J Gastroenterol Hepatol. 2007;22:1112-19.

48. Jimba S, Nakagami T, Takahashi M, Wakamatsu T, Hirota Y, Iwamoto Y, Wasad T. Prevalence of nonalcoholic fatty liver disease and its association with impaired glucose metabolism in Japanese adults. Diabet Med. 2005;22:1141-5.

49. Kashireddy PR, Rao MS. Sex differences in choline-deficient diet-induced steatohepatitis in mice. Exp Biol Med (Maywood). 2004;229:158-62.

50. Kim HJ, Kim HJ, Lee KE, Kim DJ, Kim SK, Ahn CW, Lim SK, Kim KR, Lee $\mathrm{HC}$, Huh KB, Cha BS. Metabolic significance of nonalcoholic fatty liver disease in nonobese, nondiabetic adults. Arch Intern Med. 2004;164:2169-75.

51. Kobayashi J, Maruyama T, Watanabe H, Kudoh A, Tateishi S, Sasaki T, Murano $\mathrm{S}$, Watanabe M. Gender differences in the effect of type 2 diabetes on serum lipids, pre-heparin plasma lipoprotein lipase mass and other metabolic parameters in Japanese population. Diabetes Res Clin Pract. 2003;62:39-45.

52. Kotronen A, Yki-Järvinen H. Fatty liver: a novel component of the metabolic syndrome. Arterioscler Thromb Vasc Biol. 2008;28:27-38

53. Laish I, Braun M, Mor E, Sulkes J, Harif Y, Ben Ari Z. Metabolic syndrome in liver transplant recipients: prevalence, risk factors, and association with cardiovascular events. Liver Transpl. 2011;17:15-22.

54. Lavine JE, Schwimmer JB. Nonalcoholic fatty liver disease in the pediatric population. Clin Liver Dis. 2004;8:549-58.

55. Li W, Ma D, Liu M, Liu H, Feng S, Hao Z, Wu B, Zhang S. Association between metabolic syndrome and risk of stroke: a meta-analysis of cohort studies. Cerebrovasc Dis. 2008;25:539-47.

56. Liangpunsakul $\mathrm{S}$, Chalasani N. Is hypothyroidism a risk factor for non-alcoholic steatohepatitis? J Clin Gastroenterol. 2003;37:340-3.

57. Loria P, Carulli L, Bertolotti M, Lonardo A. Endocrine and liver interaction: the role of endocrine pathways in NASH. Nat Rev Gastroenterol Hepatol. 2009;6:236-47

58. Ludwig J, Viggiano TR, McGill DB,Oh BJ. Nonalcoholic steatohepatitis: Mayo Clinic experiences with a hitherto unnamed disease. Mayo Clin Proc. 1980;55:434-8

59. Marchesini G, Brizi M, Bianchi G, Tomassetti S, Bugianesi E, Lenzi M, McCullough AJ, Natale S, Forlani G, Melchionda N. Nonalcoholic fatty liver disease: a feature of the metabolic syndrome. Diabetes. 2001;50:1844-50.

60. Marchesini G, Bugianesi E, Forlani G, Cerrelli F, Lenzi M, Manini R, Natale S, Vanni E, Villanova N, Melchionda N, Rizzetto M. Nonalcoholic fatty liver, steatohepatitis, and the metabolic syndrome. Hepatology. 2003;37:917-23.

61. Marchesini G, Marzocchi R. Metabolic syndrome and NASH. Clin Liver Dis 2007;11:105-17.

62. Marques-Vidal P, Mazoyer E, Bongard V, Gourdy P, Ruidavets JB, Drouet L, Ferrières J. Prevalence of insulin resistance syndrome in southwestern France and its relationship with inflammatory and hemostatic markers. Diabetes Care. 2002;25:1371-7.

63. McKimmie RL, Daniel KR, Carr JJ, Bowden DW, Freedman BI, Regsuter TC, Hsu FC, Lohman KK, Weinberg RB, Wagenknecht LE. Hepatic steatosis and subclinical cardiovascular disease in a cohort enriched for type 2 diabetes: the diabetes heart study. Am J Gastroenterol. 2008;103:3029-35.

64. Monnier VM. Intervention against the Maillard reaction in vivo. Arch Biochem Biophys. 2003;419:1-15.

65. National Cholesterol Education Program (NCEP) Expert Panel on Detection, Evaluation, and Treatment of High Blood Cholesterol in Adults (Adult Treatment Panel III). Third report of the National Cholesterol Education Program (NCEP) Expert Panel on Detection, Evaluation, and Treatment of High Blood Cholesterol in Adults (Adult Treatment Panel III) final report. Circulation. 2002;106:3143-421.

66. Nobili V, Alisi A, Panera N, Agostoni C. Low birth weight and catch-up-growth associated with metabolic syndrome: a ten year systematic review. Pediatr Endocrinol Rev. 2008;6:241-7.

67. Pagadala M, Dasarathy S, Eghtesad B, McCullough AJ. Posttransplant metabolic syndrome: an epidemic waiting to happen. Liver Transpl. 2009;15:1662-70.

68. Pagel JF. Obstructive sleep apnea (OSA) in primary care: evidence-based practice. J Am Board Fam Med. 2007;20:392-8.

69. Penninx BW, Nicklas BJ, Newman AB, Harris TB, Goodpaster BH, Satterfield S, de Rekeneire N, Yaffe K, Pahor M, Kritchevsky SB; Health ABC Study. Metabolic syndrome and physical decline in older persons: results from the health, aging and body composition study. J Gerontol A Biol Sci Med Sci. 2009;64:96-102.

70. Povel CM, Boer JM, Reiling E, Feskens EJ. Genetic variants and the metabolic syndrome: a systematic review. Obes Rev. 2011. 
71. Rashid M, Roberts EA. Nonalcoholic steatohepatitis in children. J Pediatr Gastroenterol Nutr. 2000;30:48-53.

72. Reaven G. Syndrome X: 10 years after. Drugs. 1999;58(Suppl 1):S19-20.

73. Rivera CA. Risk factors and mechanisms of non-alcoholic steatohepatitis. Pathophysiology. 2008;15:109-14.

74. Savransky V, Nanayakkara A, Vivero A, Li J, Bevans S, Smith PL, Torbenson MS, Polotsky VY. Chronic intermittent hypoxia predisposes to liver injury. Hepatology. 2007;45:1007-13.

75. Schwimmer JB, McGreal N, Deutsch R, Finegold MJ, Lavine JE. Influence of gender, race, and ethnicity on suspected fatty liver in obese adolescents. Pediatrics. 2005; 115:e561-5.

76. Silveira VM, Horta BL. [Birth weight and metabolic syndrome in adults: metaanalysis]. Rev Saúde Pública. 2008;42:10-8.

77. Singh DK, Sakhuja P, Malhotra V, Gondal R, Sarin SK. Independent predictors of steatohepatitis and fibrosis in Asian Indian patients with non-alcoholic steatohepatitis. Dig Dis Sci. 2008;53:1967-76.

78. Sobhonslidsuk A, Jongirasiri S, Thakkinstian A, Wisedopas N, Bunnag P, Puavilai G. Visceral fat and insulin resistance as predictors of non-alcoholic steatohepatitis. World J Gastroenterol. 2007;13:3614-8.

79. Solga SF, Clark JM, Alkhuraishi AR, Torbenson M, Tabesh A, Schweitzer M, Diehl AM, Magnuson TH. Race and comorbid factors predict nonalcoholic fatty liver disease histopathology in severely obese patients. Surg Obes Relat Dis. 2005;1:6-11.

80. Tanné F, Gagnadoux F, Chazouillères O, Fleury B, Wendum D, Lasnier E, Lebeau B, Poupon R, Serfaty L. Chronic liver injury during obstructive sleep apnea. Hepatology. 2005;41:1290-6.

81. Tarantino G, Saldalamacchia G, Conca P, Arena A. Non-alcoholic fatty liver disease: further expression of the metabolic syndrome. J Gastroenterol Hepatol. 2007;22:293-3.

82. Targher G, Bertolini L, Padovani R, Rodella S, Zoppini G, Pichiri I, Sorgato C, Zenari L, Bonora E. Prevalence of non-alcoholic fatty liver disease and its association with cardiovascular disease in patients with type 1 diabetes. J Hepatol. 2010;53:713-8

83. Tarquini R, Lazzeri C, Boddi M, Marra F, Abbate R, Gensini GF. Non-alcoholic fatty liver disease: a new challenge for cardiologists. G Ital Cardiol (Rome). 2010;11:660-9.

84. Tikkanen MJ, Nikkilä EA. Regulation of hepatic lipase and serum lipoproteins by sex steroids. Am Heart J. 1987;113:562-7.
85. Vernon G, Baranova A, Younossi ZM. Systematic review: the epidemiology and natural history of non-alcoholic fatty liver disease and non-alcoholic steatohepatitis in adults. Aliment Pharmacol Ther. 2011;34:274-85.

86. Villanova N, Moscatiello S, Ramilli S, Bugianesi E, Magalotti D, Vanni E, Zoli M, Marchesini G. Endothelial dysfunction and cardiovascular risk profile in nonalcoholic fatty liver disease. Hepatology. 2005;42:473-80.

87. Volzke H, Robinson DM, Kleine V, Deutscher R, Hoffmann W, Ludemann J, Schminke U, Kessler C, John U. Hepatic steatosis is associated with an increased risk of carotid atherosclerosis. World J Gastroenterol. 2005;11:1848-53.

88. Weltman MD, Farrell GC, Liddle C. Increased hepatocyte CYP2E1 expression in a rat nutritional model of hepatic steatosis with inflammation. Gastroenterology. 1996;111:1645-53.

89. Weltman MD, Farrell GC, Hall P, Ingelman-Sundberg M, Liddle C. Hepatic cytochrome P450 2E1 is increased in patients with non-alcoholic steatohepatitis Hepatology. 1998;27:128-33.

90. Williams CM. Cardiovascular risk factors in women. Proc Nutr Soc. 1997;56:383-91

91. Yatsuji S, Hashimoto E, Tobari M, Tokushige K, Shiratori K. Influence of age and gender in Japanese patients with non-alcoholic steatohepatitis. Hepatol Res. 2007;37:1034-43.

92. Younossi ZM, Gramlich T, Bacon BR, Matteoni CA, Boparai N, O'Neill R, McCullough AJ. Hepatic iron and nonalcoholic fatty liver disease. Hepatology. 1999;30:847-50.

93. Younossi ZM, Gramlich T, Matteoni CA, Boparai N, McCullough AJ. Nonalcoholic fatty liver disease in patients with type 2 diabetes. Clin Gastroenterol Hepatol. 2004;2:262-5.

94. Zamora-Valdés D, Méndez-Sánchez N. Experimental evidence of obstructive sleep apnea syndrome as a second hit accomplice in nonalcoholic steatohepatitis pathogenesis. Ann Hepatol. 2007;6:281-3.

95. Zein CO, Unalp A, Colvin R, Liu YC, McCullough AJ; Nonalcoholic Steatohepatitis Clinical Research Network. Smoking and severity of hepatic fibrosis in nonalcoholic fatty liver disease. J Hepatol. 2011;54:753-9.

96. Zhu X, Cheng SY. New insights into regulation of lipid metabolism by thyroid hormone. Curr Opin Endocrinol Diabetes Obes. 2010;17:408-13.

Received 25/5/2011 Accepted 5/9/2011 